\title{
QUALIDADE DE MUDAS DE MARACUJAZEIRO-AMARELO FORMADAS EM SUBSTRATOS COM DIFERENTES NÍVEIS DE LITHOTHAMNIUN ${ }^{1}$
}

\author{
Quality of yellow passion fruit formatted in substrate with \\ different level of lithothamniun
}

\author{
Vander Mendonça ${ }^{2}$, Maria Yumbla Orbes ${ }^{3}$, Nildo Antônio Arruda de Abreu ${ }^{4}$, \\ José Darlan Ramos ${ }^{5}$, Glauco Antônio Teixeira ${ }^{3}$, Henrique Antunes de Souza ${ }^{3}$
}

\begin{abstract}
RESUMO
A utilização de mudas de qualidade na formação de pomares de maracujazeiro é indispensável para obtenção de altas produtividades. Assim, com o objetivo de avaliar a qualidade de mudas de maracujazeiro-amarelo produzidas em diferentes substratos e adubadas com Lithothamniun, conduziu-se um experimento no viveiro de mudas da Universidade Federal de Lavras (UFLA), Minas

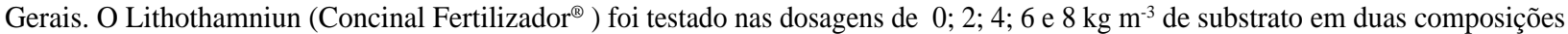
de substratos: A (composto orgânico + areia + solo na proporção de 1:1:3 em volume) e B (Plantmax ${ }^{\circledR}$ + areia + solo na proporção de 1:1:3 em volume ). Foi utilizado o delineamento experimental em blocos ao acaso em esquema fatorial $5 \times 2$, com 4 repetições e cinco plantas por parcela. Após 126 dias da semeadura foram avaliadas as características: altura de plantas (cm); número de folha/planta, comprimento de raiz, matéria seca da parte aérea, da raiz e total (g/planta). A utilização do Concinal Fertilizador ${ }^{\circledR}$ em dosagens de até $4,5 \mathrm{~kg} \cdot \mathrm{m}^{-3}$ proporcionou bons resultados na formação de mudas de maracujazeiro-amarelo (Passiflora edulis Sims f. flavicarpa Deneger). Substrato contendo composto orgânico proporcionou a formação de mudas de maracujazeiro-amarelo de melhor qualidade em comparação com substrato contendo plantmax.
\end{abstract}

Termos para indexação: Passiflora edulis f. flavicarpa., adubação, qualidade.

\begin{abstract}
An experiment was carried out at an orchard greenhouse of Universidade Federal de Lavras, Minas Gerais aiming at evaluating the growth of yellow passion fruit (Passiflora edulis Sims f. flavicarpa Deneger) seedling in different substrates. The Lithothamniun (Concinal Fertilizador ${ }^{\circledR}$ ) was tested in five doses $0 ; 2 ; 4 ; 6 ; 8 ; \mathrm{kg} \mathrm{m}^{-3}$ of substrates and two substrates compositions A: organic compost + sand +soil and B: Plantmax ${ }^{\circledR}+$ sand + soil in proportion of 1:1:3 in volume. A randomized block design was used with factorial scheme 5 x 2, with four replications and ten plants by plot. After 126 days after sowing it was evaluated the following characteristic, high of plants $(\mathrm{cm})$, root length $(\mathrm{cm})$, number of leaves/plants, and dry matter of aerial part, root and total $(\mathrm{g} / \mathrm{plant})$. Best results in the growth of yellow passion fruit plants was verified with the Concinal Fertilizador ${ }^{\circledR}$ until the dose of $4,5 \mathrm{~kg} . \mathrm{m}^{-3}$ and with the substrate A.
\end{abstract}

Index terms: Passiflora edulis f. flavicarpa., fertilization, quality.

(Recebido para publicação em 21 de outubro de 2004 e aprovado em 1 de abril de 2005)

\section{INTRODUÇÃO}

A cultura do maracujazeiro ganhou importância no Brasil a partir da década de 70, com as primeiras exportações de suco para o mercado externo. Hoje entre as frutas produzidas, o maracujazeiro está em franca expansão no Brasil, principalmente nos estados da região nordeste. Em 2001 a área plantada no País foi de 33.039 ha, com uma produção de 467.464 t (AGRIANUAL, 2004). Apesar disso, a cultura tem enfrentado vários problemas na produção, por vários fatores, entre eles o manejo inadequado da cultura, a ausência de agentes polinizadores, o déficit hídrico e a adubação incorreta, refletindo em baixa produtividade de frutos.

Na formação da muda, é importante a utilização de substratos que apresentem propriedades físico-químicas adequadas e que forneçam os nutrientes necessários para o desenvolvimento da planta (MENDONÇA et al., 2002). Segundo Silva et al. (2001), os melhores substratos devem apresentar, disponibilidade de aquisição e transporte, ausência de patógenos, riqueza em nutrientes essenciais, $\mathrm{pH}$, textura e estrutura adequadas.

Diferentes formulações de substratos têm sido utilizadas na formação de mudas de maracujazeiro, com

\footnotetext{
1 Trabalho financiando com bolsa da CAPES e CNPq

${ }^{2}$ Engenheiro Agrônomo, Dr. Professor Adjunto da Universidade Estadual de Mato Grosso do Sul/UEMS - Rod. MS 306 , Km 6 - $79.540-000$ Cassilândia, MS - vanderm@uems.br

${ }^{3}$ Alunos(a) de graduação em Agronomia pelaUniversidade Federal de Lavras/UFLA - Cx. P. 3037 - $37200-000$ - Lavras, MG.

${ }^{4}$ Engenheiro Agrônomo do Departamento de Agricultura - Universidade Federal de Lavras/UFLA - Cx. P. 3037 - $37200-000$ - Lavras, MG.

${ }^{5}$ Engenheiro Agrônomo, Dr. Professor do Departamento de Agricultura - Universidade Federal de Lavras/UFLA - Cx. P. 3037 - $37200-000$ - Lavras, MG darlan@ufla.br
} 
obtenção de bons resultados (BELLÉ \& KÄMPF, 1993; MACHADO, 1998; PEIXOTO et al., 1999).

Apesar do conhecimento já alcançado para a correção da acidez e melhoria da fertilidade natural do solo, a busca por novos insumos agrícolas é de suma importância para uma agricultura sustentável e ecologicamente viável. Nesse contexto, é imperativo que se conheçam os fatores que influenciam a disponibilidade dos nutrientes, advindos da correção do solo e melhoria da sua fertilidade, pelo uso de novos insumos, entre eles um produto fertilizante de ação corretiva de acidez do solo, como é o caso do Lithothamniun, um material derivado de algas marinhas calcáreas, de nome comercial Concinal Fertilizador ${ }^{\circledR}$ (MELO \& FURTINI NETO, 2003).

O Lithothamniun é retirado do fundo do mar, do sedimento marinho, na plataforma continental do Espírito Santo e estocado no pátio da fábrica por um período variável. Após a primeira trituração, é seco ao ar quente e micropulverizado a frio. Este produto apresenta uma atividade muito intensa no solo, principalmente devido à elevada superfície específica do material (LOPEZ-BENTO, 1963).

O Lithothamniun (Concinal Fertilizador ${ }^{\circledR}$ ) apresenta em sua composição química Ca $32 \% ; \mathrm{Mg} 2 \% ; \mathrm{S} 0,2 \% ; \mathrm{Cl}$ 0,2\%; Mo 0,0005\% e Fe 0,1\% (KEMPF, 1974).

Com objetivo de testar a viabilidade do uso de Lithothamniun (Concinal Fertilizador ${ }^{\circledR}$ ) em diferentes substratos para produção de mudas de maracujazeiroamarelo, foi realizado este experimento.

\section{MATERIAL E MÉTODOS}

O experimento foi desenvolvido no período de abril a agosto de 2004, em um viveiro coberto com telado de nylon tipo sombrite, com redução de 50\% de luminosidade, localizado no Setor de Fruticultura da Universidade Federal de Lavras (UFLA), no município de Lavras-MG. O clima da região é temperado suave (mesotérmico), tipo $\mathrm{Cwb}$. O município está localizado a uma altitude de 913 metros, $21^{\circ} 14^{\prime} 06^{\prime \prime}$ latitude $\mathrm{S}$ e $45^{\circ} 00^{\prime} 00^{\prime \prime}$ longitude $\mathrm{O}$, tem precipitação média anual de 1493,2 mm, ocorrendo uma maior concentração entre os meses de novembro e fevereiro. Sua temperatura média anual é $19,3{ }^{\circ} \mathrm{C}$ e umidade relativa do ar é 80\% (CASTRO NETO \& SILVEIRA, 1981).

As sementes do maracujazeiro-amarelo foram coletadas de frutos de plantas do pomar do Setor de Fruticultura da UFLA. Os substratos A (composto orgânico + areia + solo na proporção de 1:1:3 em volume) e B (Plantmax ${ }^{\hat{a}}+$ areia + solo na proporção de 1:1:3 em volume) foram preparados, sendo adicionados aos mesmos o Lithothamniun (Concinal Fertilizador ${ }^{\circledR}$ ) nas dosagens de $0 ; 2 ; 4 ; 6$ e $8 \mathrm{~kg} \mathrm{~m}^{-3}$. Foram utilizados sacos de polietileno com capacidade de $500 \mathrm{~mL}$.

As sementes foram lavadas em água corrente, utilizando-se cal virgem para extração da mucilagem, sendo em seguida colocadas para secar à sombra por 3 dias. Em seguida, foram semeadas, colocando-se três sementes por recipientes os quais receberam as diferentes dosagens de Lithothamniun (Concinal Fertilizador ${ }^{\circledR}$ ).

Após a germinação, cerca de 15 dias da semeadura, as mudas foram desbastadas deixando-se apenas a muda mais vigorosa por recipiente.

Foi utilizado o delineamento experimental em blocos ao acaso em esquema fatorial $5 \times 2$, com 4 repetições e cinco plantas por parcela. Os resultados da análise química dos diferentes substratos estão nas Tabelas 1 e 2.

A duração do experimento foi de 126 dias, quando as mudas apresentavam altura adequada para serem transplantadas para o campo. Foram avaliadas as seguintes características: altura da muda $(\mathrm{cm})$; comprimento da raiz $(\mathrm{cm})$; número de folhas/planta; matéria seca da parte aérea, da raiz e total $(\mathrm{g})$.

TABELA 1 - Resultados da análise físico-química dos substratos utilizados no experimento com maracujazeiro-amarelo, realizada pelo Laboratório de Fertilidade do Solo da UFLA ${ }^{1}$.

\begin{tabular}{|c|c|c|c|c|c|c|c|c|c|c|c|c|c|}
\hline Substrato & PH & $\mathbf{P}$ & $\mathbf{K}$ & $\mathbf{C a}$ & Mg & Al & $\mathbf{H}+\mathbf{A l}$ & SB & $\mathbf{t}$ & $\mathbf{T}$ & $\mathbf{V}$ & M.O & P-rem \\
\hline & $\mathrm{H}_{2} \mathrm{O}$ & \multicolumn{2}{|c|}{$\mathrm{mg} \mathrm{dm}^{-3}$} & \multicolumn{7}{|c|}{ 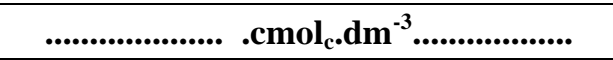 } & dag.kg ${ }^{-1}$ & $(\%)$ & $\mathbf{m g ~ L ^ { - 1 }}$ \\
\hline A & 6,0 & 15 & 72 & 4,0 & 1,4 & 0,0 & 1,9 & 5,6 & 5,6 & 7,5 & 74,6 & 1,6 & 15,1 \\
\hline $\mathrm{B}$ & 5,7 & 49,8 & 186 & 5,1 & 1,8 & 0,0 & 2,3 & 7,4 & 7,4 & 9,6 & 76,2 & 1,9 & 12,2 \\
\hline
\end{tabular}

${ }^{1} \mathrm{SB}$ - soma de bases; t- CTC efetiva; T- CTC a pH 7,0; V - saturação de bases 
TABELA 2 - Resultados da análise de micronutrientes nos substratos no experimento com maracujazeiro-amarelo, realizada pelo Laboratório de Fertilidade do Solo da UFLA.

\begin{tabular}{cccccc}
\hline Substrato & Zn & Fe & Mn & Cu & B \\
\hline \multicolumn{7}{c}{$\mathbf{~ m g ~ d m}^{-3}$} \\
A & 3,4 & 49,6 & 20,7 & 2,0 & 1,0 \\
B & 1,9 & 118,2 & 23,1 & 2,1 & 0,9 \\
\hline
\end{tabular}

A altura da muda foi obtida medindo-se a distância entre o colo e o ápice da muda. O comprimento da raiz foi obtido medindo-se a distância entre o colo e a extremidade da raiz. A matéria seca da parte aérea e da raiz foram obtidas após secagem em estufa de circulação forçada de ar a 60 ${ }^{\circ} \mathrm{C}$, até atingirem peso constante, procedendo a pesagem em balança analítica.

Os dados foram submetidos à análise de variância e as médias ao teste Tukey, ao nível de 5\% de probabilidade (GOMES, 2000). As análises foram realizadas pelo programa computacional Sistema para Análise de Variância - SISVAR (FERREIRA, 2000).

\section{RESULTADOS E DISCUSSÃO}

Verificou-se pelos resultados da análise de variância apresentados na Tabela 3, que as duas misturas de substrato apresentaram diferenças significativas pelo teste $\mathrm{F}(\mathrm{P}<0,05)$, para as variáveis comprimento da raiz, número de folhas e matéria seca da raiz. As diferentes doses do Concinal Fertilizador ${ }^{\hat{a}}$ proporcionaram diferenças significativas pelo teste $\mathrm{F}(\mathrm{P}<0,01)$ para todas as variáveis, com exceção para o comprimento da raiz.

O máximo crescimento da parte aérea das mudas de maracujazeiro $(18,36 \mathrm{~cm})$ foi alcançado com a utilização de $4,38 \mathrm{~kg} \mathrm{~m}^{-3}$ de Concinal Fertilizador ${ }^{\hat{a}}$ (Figura 1). Esse crescimento corresponde a um ganho em torno de $27,7 \%$ em relação ao tratamento testemunha (sem utilização do fertilizante).

O maior comprimento de raíz $(17,02 \mathrm{~cm})$ foi obtido no substrato $A$, sendo este valor estatisticamente diferente do substrato B, cujo valor para esta variável foi de 16,22 cm (Figura 2). A resposta para o número de folhas teve um comportamento linear em relação a adição de Concinal Fertilizador ${ }^{\hat{a}}$, sendo a dose de $8 \mathrm{~kg} \cdot \mathrm{m}^{-3}$ a que proporcionou maior número de folhas $(8,65)$ (Figura 3 ). Em relação aos substratos o A foi o que também se destacou com média de 8,26 folhas por muda (Figura 2).

A matéria seca de parte aérea das mudas (Figura 4) apresentou comportamento quadrático, sendo que o valor máximo para esta variável ( $1,55 \mathrm{~g})$ foi obtido na dose de $4,59 \mathrm{~kg} \cdot \mathrm{m}^{-3}$ do fertilizante. Esse valor é bem superior ao observado sem a utilização do fertilizante que foi de apenas 0,63 g. O valor máximo da matéria seca da raiz $(0,46$ g) foi alcançado com a utilização do Concinal Fertilizador ${ }^{a}$ na dose de 4,29 kg.m ${ }^{-3}$ (Figura 5). Em relação ao substrato, a melhor resposta $(0,36 \mathrm{~g})$ foi observada quando se utilizou o substrato A (Figura 2).

A matéria seca total, característica que expressa melhor o efeito das doses do fertilizante e dos substratos na formação da muda, só foi influenciada pelo fertilizante. Verificou-se um comportamento quadrático em relação as doses do fertilizante, sendo que na dose $4,50 \mathrm{~kg} \cdot \mathrm{m}^{-3}$ a matéria seca total alcançou seu valor máximo $(2,01 \mathrm{~g})$, correspondendo a um ganho em torno de $260 \%$ em comparação a testemunha sem a utilização do fertilizante (Figura 6).

O modelo que melhor se ajustou aos dados obtidos para diversas variáveis foi o quadrático, indicando um aumento de qualidade das mudas de maracujazeiro-amarelo com aplicações de doses crescentes do Lithothamniun até atingir um ponto máximo, a partir do qual as mudas tiveram efeito depressivos.

Melo et al. (2003), estudando a utilização de Lithothamniun fertilizante como corretivo da acidez do solo e fonte de nutrientes para o feijoeiro, concluíram que este fertilizante promoveu elevação dos teores de cálcio e magnésio nas plantas, resultando em melhores condições de nutrição, crescimento e produção.

Miranda (1985), testando calcário magnesiano comercial e dois calcários marinhos (Lithothamne $\mathrm{C}$ e Lithothamne 400), de procedência francesa, em dois Latossolos, LE e LV, como corretivos de acidez do solo, concluiu que os calcários marinhos são como corretivos da acidez do solo, quando aplicados em quantidades semelhantes a do calcário comercial, e que o uso destes calcários marinhos não dispensaria, porém, a aplicação de micronutrientes para a cultura do milho-grão, cultivada em solos deficientes nesses elementos. 
TABELA 3 - Resumo da análise de variância da altura da muda, comprimento da raiz, número de folhas, matéria seca da parte aérea, da raiz e total em função de doses de Concinal Fertilizador ${ }^{\circledR}$ e substratos na produção de mudas de maracujazeiro-amarelo. Lavras-MG, 2004.

\begin{tabular}{cccccccc}
\hline $\begin{array}{c}\text { Fontes de } \\
\text { Variação }\end{array}$ & GL & $\begin{array}{c}\text { Altura da } \\
\text { muda }(\mathbf{c m})\end{array}$ & $\begin{array}{c}\text { Comprimento } \\
\text { da raiz }(\mathbf{c m})\end{array}$ & $\begin{array}{c}\mathbf{N}^{\circ} \text {.de } \\
\text { folhas }\end{array}$ & $\begin{array}{c}\text { Matéria seca da } \\
\text { parte aérea }(\mathbf{g})\end{array}$ & $\begin{array}{c}\text { Matéria seca } \\
\text { da raiz }(\mathbf{g})\end{array}$ & $\begin{array}{c}\text { Matéria secs } \\
\text { total }(\mathbf{g})\end{array}$ \\
\hline Concinal $^{\circledR}(\mathrm{C})$ & 4 & $35,862534^{* *}$ & $0,654184 \mathrm{~ns}$ & $1,709125^{* *}$ & $1,044685^{* *}$ & $0,149327^{* *}$ & $1,959932^{* *}$ \\
Substrato $(\mathrm{S})$ & 1 & $16,926010 \mathrm{~ns}$ & $6,336160^{*}$ & $2,070250^{*}$ & $0,051122 \mathrm{~ns}$ & $0,043824^{*}$ & $0,189613 \mathrm{~ns}$ \\
$\mathrm{C} \mathrm{x} \mathrm{S}$ & 4 & $14,716529 \mathrm{~ns}$ & $0,539491 \mathrm{~ns}$ & $0,238375 \mathrm{~ns}$ & $0,146708 \mathrm{~ns}$ & $0,012382 \mathrm{~ns}$ & $0,215973 \mathrm{~ns}$ \\
Bloco & 3 & 4,422150 & 0,259950 & 0,954250 & 0,083865 & 0,013828 & 0,072950 \\
Resíduo & 27 & 8,055659 & 0,849470 & 0,340176 & 0,105543 & 0,008521 & 0,132469 \\
\hline CV $(\%)$ & & 17,18 & 5,55 & 7,26 & 26,61 & 28,08 & 23,49 \\
\hline
\end{tabular}

** Significativo a $1 \%$ de probabilidade pelo teste F; * Significativo a $5 \%$ de probabilidade pelo teste $\mathrm{F}$ e ns Nãosignificativo

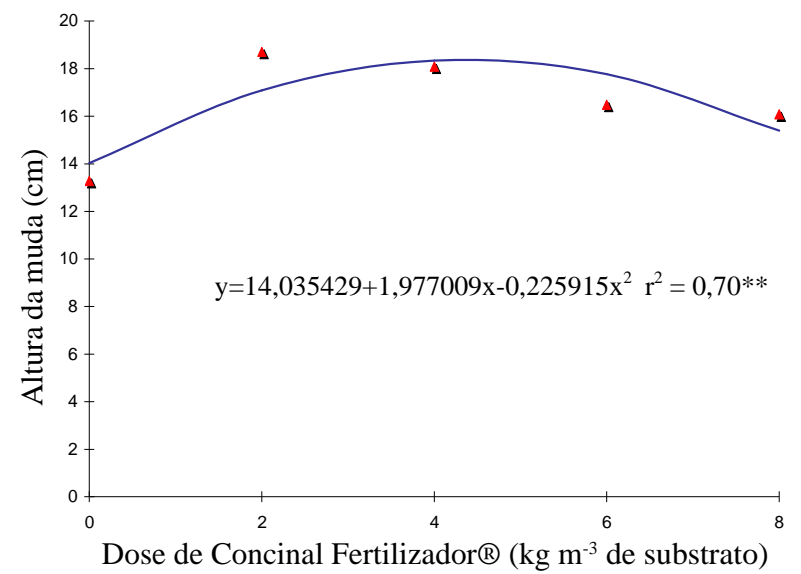

FIGURA 1 -Efeito das doses do Concinal Fertilizador ${ }^{\circledR}$ na altura da muda de maracujazeiro-amarelo. Lavras-MG, 2004.

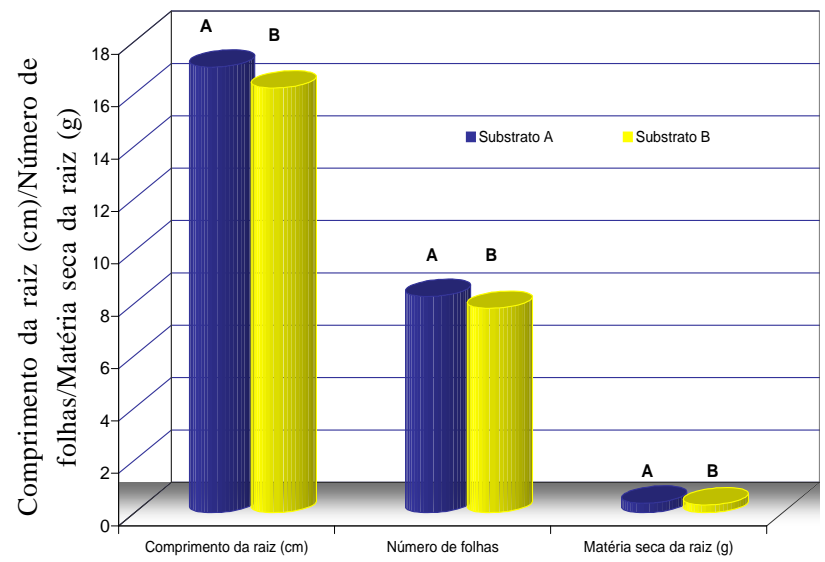

FIGURA 2 - Comprimento da raiz, número de folhas e matéria seca da raiz de mudas de maracujazeiro-amarelo em função dos diferentes substratos. Letras indicam diferenças estatística pelo teste de Tukey a 5\%. Lavras-MG, 2004. 


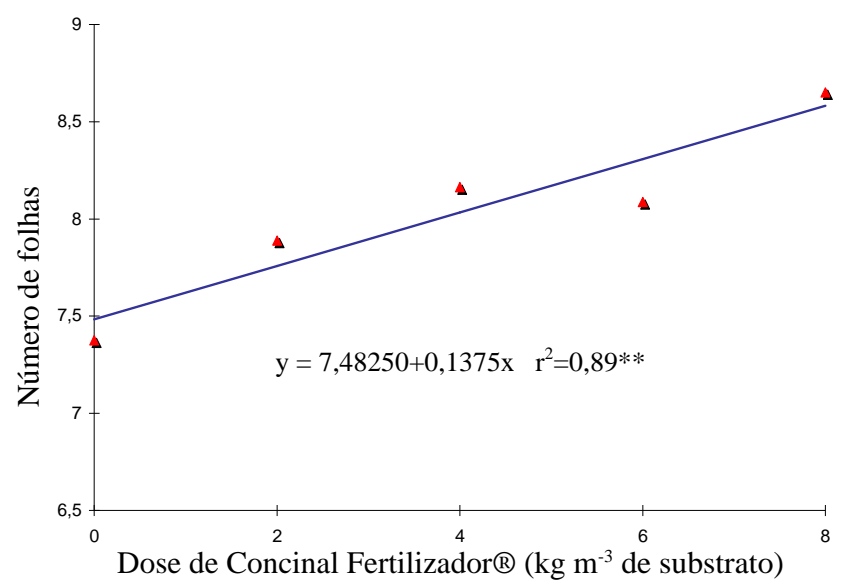

FIGURA 3 - Efeito das doses do Concinal Fertilizador ${ }^{\circledR}$ no número de folhas de mudas de maracujazeiro-amarelo. Lavras-MG, 2004.

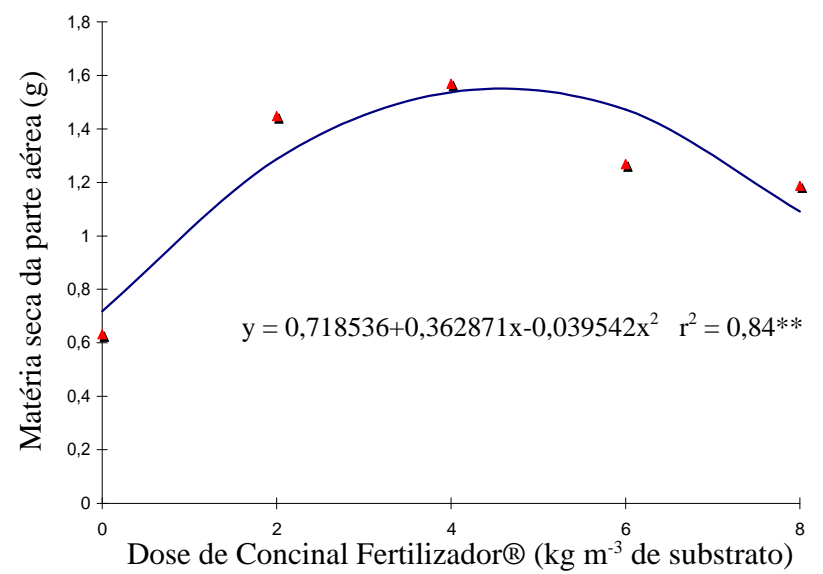

FIGURA 4 - Efeito das doses do Concinal Fertilizador ${ }^{\circledR}$ na matéria seca da parte aérea de mudas de maracujazeiroamarelo. Lavras-MG, 2004.

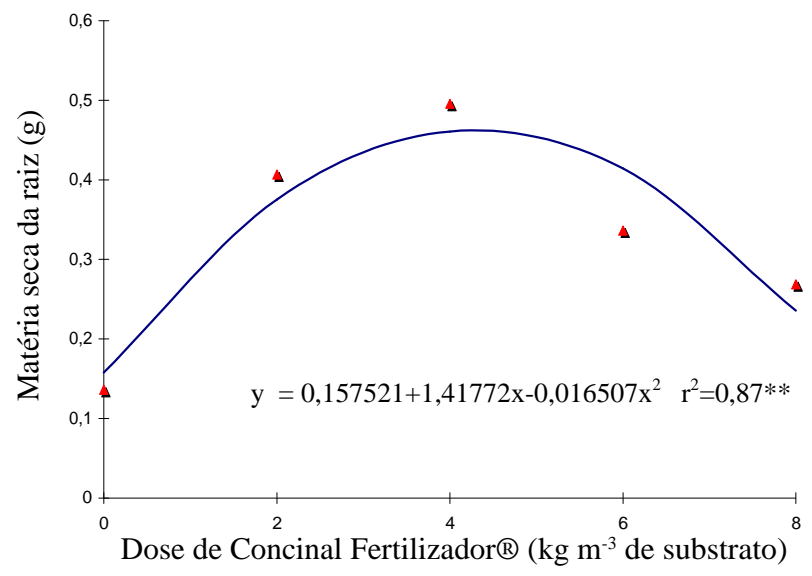

FIGURA 5 - Efeito das doses do Concinal Fertilizador ${ }^{\circledR}$ na matéria seca da raiz de mudas de maracujazeiro-amarelo. Lavras-MG, 2004.

Ciênc. agrotec., Lavras, v. 30, n. 5, p. 900-906, set./out., 2006 


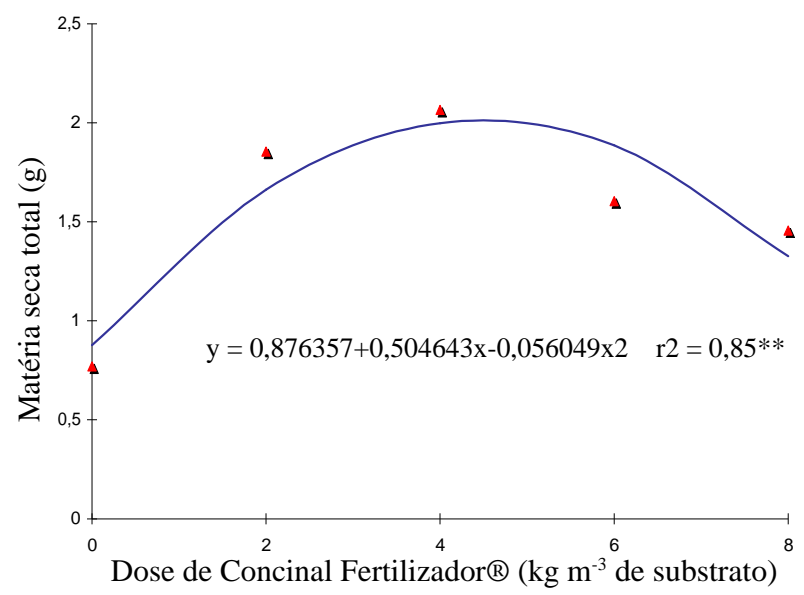

FIGURA 6 - Efeito das doses do Concinal Fertilizador ${ }^{\circledR}$ na matéria seca total de mudas de maracujazeiro-amarelo. Lavras-MG, 2004.

\section{CONCLUSÕES}

A utilização do Lithothamniun (Concinal Fertilizador $\left.^{\hat{a}}\right)$, em doses de até $4,5 \mathrm{~kg} \cdot \mathrm{m}^{-3}$, proporcionou bons resultados na formação de mudas de maracujazeiro-amarelo.

Doses elevadas do Lithothamniun, resultaram em efeitos depressivos nas mudas.

O substrato A (composto orgânico + areia + solo na proporção de 1:1:3 em volume) proporcionou maior comprimento de raiz, número de folhas e matéria seca da raiz nas mudas de maracujazeiro-amarelo.

\section{REFERÊNCIAS BIBLIOGRÁFICAS}

AGRIANUAL. Anuário estatístico do Brasil. São Paulo: FNP Consultoria \& Comércio, 2004. 536 p.

BELLÉ, S.; KÄMPF, A. N. Produção de mudas de maracujáamarelo em substratos à base de turfa. Pesquisa Agropecuária Brasileira, Brasília, v. 28, n. 3, p. 385-390, 1993.

CASTRO NETO, P.; SILVEIRA, S. V. Precipitação provável para Lavras, Região Sul de Minas Gerais, baseada na função de distribuição de probabilidade gama: 1 . período mensal. Ciência e Prática, Lavras, v. 5, n. 2, p. 144-151, jul./dez. 1981.

FERREIRA, D. F. Análise estatística por meio do SISVAR (Sistema para Análise de Variância) para Windows versão 4.0. In: REUNIÃO ANUAL DA REGIÃO BRASILEIRA DA SOCIEDADE INTERNACIONAL DE BIOMETRIA, 45., 2000, São Carlos. Anais... São Carlos: UFSCar, 2000. p. 255-258.
GOMES, F. P. Curso de estatística experimental. 14. ed. Piracicaba: USP, 2000. 477 p.

KEMPF, M. Perspectivas de exploração econômica dos fundos de algas calcárias da plataforma continental do Nordeste do Brasil. Recife: UFPE, 1974. 22 p. (Trabalho oceanofráfico, 14).

LOPEZ-BENTO, M. Estudio de la composición quimica del Lithothamnium calcareum (Aresch) y su aplicación como corretor del terrenos de cultivo. Inv. Pesq., [S.1.], v. 23, p. 53-70, jun. 1963.

MACHADO, R. A. F. Fósforo e zinco na nutrição e crescimento de mudas de maracujazeiro amarelo (Passiflora edulis f. flavicarpa DEG.). 1998. $93 \mathrm{f}$. Dissertação (Mestrado) - Universidade Federal de Lavras, Lavras, 1998.

MELO, P. C. de; FURTINI NETO, A. E. Avaliação do Lithothamnium como corretivo da acidez do solo e fonte de nutrientes para o feijoeiro. Ciência e Agrotecnologia, Lavras, v. 27, n. 3, p. 508-519, maio/jun. 2003.

MENDONÇA, V.; RAMOS, J. D.; ARAÚJO NETO, S. E. de; PIO, R.; GONTIJO, T. C. A.; JUNQUEIRA, K. P. Substratos e quebra de dormência na formação do portaenxerto de gravioleira cv. RBR. Revista Ceres, Viçosa, v. 49, n. 286, p. 657-668, nov./dez. 2002. 
MIRANDA, L. N. Utilização de calcários marinhos como corretivos de acidez do solo. Revista Brasileira de Ciências do solo, Campinas, v. 9, n. 1, p. 245-248, jan./ mar. 1985.

PEIXOTO, J. R.; PAIVA JUNIOR, M. C.; ANGELIS, B.; OLIVEIRA, J. A. Adubação orgânica e fosfatada no desenvolvimento de mudas de maracujazeiro amarelo
(Passiflora edulis Sims f. flavicarpa Deneger). Revista Brasileira de Fruticultura, Jaboticabal, v. 21, p. 49-51, 1999.

SILVA, R. P. da; PEIXOTO, J. R.; JUNQUEIRA, N. T. V. Influência de diversos substratos no desenvolvimento de mudas de maracujazeiro azedo (Passiflora edulis Sims f. flavicarpa DEG). Revista Brasileira de Fruticultura, Jaboticabal, v. 23, n. 2, p. 377-381, ago. 2001. 